\title{
SYSTEMATIC QUALITY MANAGEMENT IN VOCATIONAL EDUCATIONAL INSTITUTES: ROLES OF TEACHERS IN DEVELOPMENT OF ORGANIZATIONAL QUALITY
}

\author{
${ }^{1}$ Gisela Wiesner, ${ }^{2}$ Nurhening Yuniarti \\ ${ }^{1}$ Institut für Berufspädagogik und Berufliche Didaktiken, Technische Universität Dresden, Germany \\ ${ }^{2}$ Department of Electrical Engineering Education, Universitas Negeri Yogyakarta, Indonesia \\ Email: Gisela.wiesner@tu-dresden.de
}

\begin{abstract}
A quality management system for vocational educational institutes is a system aimed at ensuring the quality goals of vocational education are achieved to meet the quality standards and develop the quality work. In practice, teachers play a vital role because the key elements in a quality assurance system are strongly related to teachers especially the learning process as the spearhead of the success of vocational education. In addition, most activities undertaken in vocational education involve teacher participation. Therefore, teachers hold a great responsibility in the successful implementation of the educational quality management system. The main point to be emphasized is how a teacher has a suitable common understanding of quality. Understanding the quality drives all activities undertaken by teachers to be quality improvement oriented.
\end{abstract}

Keywords: teacher, quality management system, quality securing and development, vocational education

\section{INTRODUCTION}

The main challenge facing vocational education is how to manage, secure and develop quality. The quality assurance should be developed by vocational education institutions to ensure the quality in its provision of skilled workers (Gatt \& Faurschou, 2016). Quality is relative. Each individual or each group has different views of quality. Therefore, a suitable common quality understanding is required to determine standards for quality. Harvey \& Green (1993) argues that each has a different perspective on quality. This is not a different perspective on the same thing but different perspectives on different things with the same label. In general, quality means the degree or superiority of a product or service, whether tangible (material) or intangible (non-material). Quality is also defined as the condition of the fulfillment of agreed standards which are testable by criteria.

Understanding quality in the context of education refers to the input (preconditions), educational process and educational outcomes. Vocational education which is designed to develop (enhance and empower) graduates, which are competent for work, need to put their emphasis on quality. The quality of vocational education is indicated from the quality of the existing processes. This quality is determined by various factors determined not only by the input quality as it once was widely assumed but also greatly influenced by the process. Therefore, the learning-teaching process is considered as an important step in the quality evaluation output (and later outcome).

Vocational education should be prepared with flexible and dynamic management principles in order to develop in accordance with their respective potential and to satisfy the external demands. The developed strategy to be used in education quality management is that an educational institution position itself as a service institute which is the industry to provide services in accordance with goals desired by the different customers (like enterprises, society or parents). Obviously, the customers always expect high-quality services to obtain great achievements and satisfaction, therefore to model high standards for vocational education institutes, a suitable quality management 
system is necessary. Djatmiko (2016) pointed out that education implementation obviously requires quality assurance management. Quality management system is substantial to build the efficiency of a vocational education system to produce human resources with dedication, commitment, and professionalism (Felestin \& Triyono, 2015). Furthermore, Al-Ali (2016) and Irimiea \& Serban (2015) suggest that Human Resources graduated from Vocational and Technical Education and Training are expected to acquire the level of knowledge, skills and attitudes that satisfy both business and industries. In this point, the quality assurance system has a role to maintain high standards of vocational education and training.

The main target in the quality management system is internal and external customer's satisfaction. In vocational education, the internal customers consist of especially principals or leaders, teachers, staff or institutional organizers. While the external customers include the community, the government, the business, and industrial world. In consequence, an educational institution is considered to be high quality if both internal and external customers obtain great satisfaction with the provided services.

In addition, high-quality vocational education institutions need to meet quality in fact and in perception. Quality, in fact, is a predetermined quality standard while quality in perception is an expected quality based on the demands and needs of service users. Skrzypek (2006) conveys the quality of education as the skill of building the abilities to assimilate the knowledge in the area of educational needs and the implementation of this knowledge to creating mechanisms allowing to fulfill expectations of customers and educational service. One should distinguish pupils, students, teachers, and employers among the people who are interested in the quality of education. Thus, the quality of education is the fulfillment of predetermined standards with regard to customers' needs and satisfaction.
The identification of quality in vocational education can be directed to different parts namely (1) vision and values, (2) leadership, (3) organization of teaching and learning, (4) management arrangements describing those aspects of the school's organization chosen by the members of an organization to help them conducting their affairs and realise their aims, (5) staff development, and (6) relationship with the community and the district.

Educators have significant roles in the quality management system of vocational education ranging from school policy determination, curriculum design, learning plan, learning implementation, learning evaluation, students' potential development and so on. Yuniarti (2014) said that a teacher is the main actor in the process of transferring knowledge and a teacher also has a strategic role in the teaching learning process. Education without high qualified teachers is paralyzed. The qualification of teachers is a crucial element in vocational education (Singh et al, 2015).Competent teacher is form of quality assurance for students' learning (Ismail et al., 2107). Hopkins (1996) states that a teacher is the heart of educational improvement. A teacher can be seen as key to the effectiveness of quality system implementation. Suitable quality management systems in vocational education demand the role of teachers as the main quality promoter. In addition, teachers deal directly with students, communicate with parents, and work with leaders and different stakeholders. But the institution as an organization has to make best preconditions for it in kind of systematic support.

\section{Quality Management System (QMS) - Definition and Function}

A quality management system (QMS) is defined as a frame model as a tool for systemic securing and development of quality (of institute and services) on basis of standards and criteria in the field of organization and product 
or services. It includes evaluation of organizational structure, procedures, processes, and resources. In the context of vocational education, QMS is a must for vocational education to be implemented according to the established goals of preparing graduates to be qualified workers to enter the workforce. When we concern designing and implementing the quality management system at the institution we should take into account that this is the long-term process which should be realized in stages, at the significant and sustained support from the side of the institution. After implementing the system, its elements should be permanently improved. (Michalska-Ćwiek, 2009).

To implement a suitable QMS, it needs preconditions. Without to know and accept these, it will not be successful to work with QMS in vocational educational institutions. The preconditions consist of (1) to steer quality management on basis of a suitable QMS is a leadership task. But the executive uses the support by a quality steering group or a commissioner for quality, (2) the executive has to secure, that all of the staff, students, and different groups of stakeholder are integrated and can participate in the development of quality. It needs a corporate culture with a useful communication, helpful feedback and high commitment, (3) usefulness of work with a suitable QMS is to make transparent for all in the vocational educational institution. It is to develop awareness, that all understand the achievement of QMS for the organization and all individuals. It has to be reached, that all in organization including staff and students are responsible for quality and have to participate in development of core processes especially learning and teaching, and results of vocational educational institution, and (4) it is to make understandable, that using QMS is not an additional task, but a tool for continuous development of higher quality of organization, all internal person, like staff, leaders or executive, students, and also for higher reputation of external person or stakeholder like enterprises, administrations, society.

\section{Advantage of Using a Suitable QMS}

Advantages of using a suitable QMS is not only successful for vocational educational institutes. It is also a contribution to the development of society. Responsible authorities and enterprises can have a big influence to develop this systemic quality work and promote it. To use a suitable QMS is an investment in vocational educational institutes as the organization and all individuals in schools, in enterprises and administrations for getting high qualified and motivated graduates and in society for having individuals, which are able and have the willingness to support the development of society.

As an example, it is shown educational policy for vocational school area in Germany. The subcommittee for Vocational Education of Regular Conference of Educational Ministries of Countries in Germany has published an important paper on quality development in vocational educational schools in 2014. They have developed and argued theses on the advantage of vocational educational schools, which use a QMS. Some keywords for better results are for examples (1) more constructive, transparent and sustainable educational political and pedagogical changings and innovation, (2) higher professionalism (as institution) for designing pedagogical and organizational processes, in same time higher professionalism of teachers, and (3) support development of school culture and better development of corporate identity.

\section{Using of QMS in Vocational Educational Institutes}

Germany is an advanced country in vocational education. The main factor that drives the advancement of vocational education in Germany is a close relationship between 
vocational education and industries. In addition, there is strong commitment and also the necessity in competition on the market to implement a suitable quality management system. Quality management supports organizational development and its services. It is aimed at achieving quality goals through planning, monitoring, assuring and improving quality.

The suitability of any QMS can be detected by necessary features. Each suitable QMS is been described as a frame model including quality area (e.g. processes) and their differentiation in quality dimensions (as fields for action in each quality area). It includes needs based standards, criteria, and indicators for evaluation for all dimensions or fields of activity for analyzing current level of quality. It demands the steering by leadership, supported by quality steering group needs for quality development participation of staff and students. It uses quality understanding as the core. It works with the quality cycle of planning, doing, checking, and acting permanently and needs to document the results. On this basis, it is possible to deduce consequences for the development of quality. It gives support by instructions and tools. It integrates quality of core processes, learning-teaching process, leading processes and support processes, also considers influences by the social and economic environment. It has integrated internal evaluation as a duty, also management review for seeing the reached quality and decision on changing. It should be possible to connect internal evaluation with external evaluation.

The decision for using a specific QMS depends very often on the ministry of education in each country. In this case, vocational schools have no possibility to choose another suitable QMS. The following describes the application of some quality management systems (QMS) for vocational schools as examples. The first QMS is Q2E which means quality by evaluation and development (Qualität durch Evaluation und Entwicklung, 2E means the beginning of German words; Evaluation and Entwicklung). This QMS is adapted from Switzerland and used for schools in Bavaria or Germany. Q2E model is a way of improving quality management system based on evaluation and development. Q2E has offered instruments to develop quality school standards based on best practice results, instruments used for quality measurement, concepts and assumptions used for teaching quality, and discussions with experts in school research and development. Four areas of quality in Q2E consist of quality of input, process quality of school (management), process quality of learning and teaching and quality of output or outcome Each of these quality areas is spelled out in 3 dimensions of quality thus Q2E quality consists of 12 dimensions presented in Table 1 (comp. Fachhochschule Nordschweiz, 2007).

Table 1. Quality Dimensions in Q2E

\begin{tabular}{|c|c|c|}
\hline No & Quality Area & Dimension \\
\hline 1. & $\begin{array}{l}\text { Quality of } \\
\text { input }\end{array}$ & $\begin{array}{l}\text { 1. Strategic framework } \\
\text { and agreement } \\
\text { 2. Personnel requirements } \\
\text { and task structure } \\
\text { 3. Material and financial } \\
\text { resources }\end{array}$ \\
\hline 2. & $\begin{array}{c}\text { Process } \\
\text { quality of } \\
\text { school } \\
\text { (management) }\end{array}$ & $\begin{array}{l}\text { 1. Leadership } \\
\text { 2. School organization } \\
\text { and administration } \\
\text { 3. School culture and } \\
\text { cooperation with } \\
\text { colleagues }\end{array}$ \\
\hline 3. & $\begin{array}{c}\text { Process } \\
\text { quality of } \\
\text { learning and } \\
\text { teaching }\end{array}$ & $\begin{array}{l}\text { 1. Social relationships } \\
\text { and leadership in } \\
\text { the classroom } \\
\text { 2. Teaching } \\
\text { Management } \\
\text { 3. Exam and } \\
\text { assessment }\end{array}$ \\
\hline 4. & $\begin{array}{l}\text { Quality of } \\
\text { output/ } \\
\text { outcome }\end{array}$ & $\begin{array}{l}\text { 1. Satisfaction and } \\
\text { acceptance of results } \\
\text { 2. Learning outcomes and } \\
\text { socialization } \\
\text { 3. School and career } \\
\text { process }\end{array}$ \\
\hline
\end{tabular}


The second QMS is QmbS which means quality management for vocational schools (State Office for School and Education of Germany, 2007). It is based on Q2E and developed and used in Bavaria or Germany. QmbS consists of five components that consists of (1) school-specific quality understanding (2) internal evaluation, (3) individual feedback, (4) external evaluation, and (5) steering of quality processes. The third QMS is a frame model of school quality from Saxony in Germany. Landesamtes für Schule und Bildung also known as State Office for School and Education of Germany (2014) states that the quality framework in Saxony consist of six quality areas and twenty nine quality characteristics. These are presented in Table 2.

In all shown examples on QMS of schools, it is to see in the areas and dimensions that teachers are not only in the focus in teaching and learning processes and their quality, their role for securing and development of school is wider. They should take a part in designing school quality in all areas because they can positively influence good frame conditions for teaching and learning processes. They can support with their ideas and continuous feedback for developing quality and they should not only have the duty for own professional development, they should have the right to get the best possibilities for their own development.

\section{Evaluation as Part of QMS}

Based on the model of the quality management system, evaluation is a very important part of the quality assurance system. Spiel (2001) states that evaluation is, in a broad sense, concerned with the effectiveness of the program. Hopkins et al. in Cullingford (2000) add that evaluation is an integral element in school improvement. While Rossi et.al. (2004) explain that evaluation typically involves assessment of one or more of five program domains namely (1) the need for the program, (2) the design of the program, (3) program implementation and service delivery, (4) program impact or outcomes, and (5) program efficiency. An evaluation must be tailored to the political and organizational context of the program being evaluated. It confirms that an evaluation can be used to assess the efficiency and effectiveness of the program as an integral element in vocational education improvement. For making an evaluation, it is to decide for which dimensions in the organization it is necessary and who should be involved. Figure 1 presents the evaluation and quality securing model in education from Ditton (2002).

Table 2. Quality Framework in Saxony

\begin{tabular}{cl}
\hline \multicolumn{1}{c}{ Quality Area } & \multicolumn{1}{c}{ Dimension } \\
\hline Results & Fulfilling educational mission \\
& The success of school and education \\
& Satisfaction on the school \\
Teaching and learning & Organization of teaching and learning \\
& Teaching and learning processes \\
Culture of school & Values and norms of the school \\
& The climate of the school \\
& Individual support \\
Professionality Development & Systematic collaboration in colleges \\
& Lifelong learning \\
Management and leadership & Administration and management of resources \\
& Leadership \\
& Quality securing and quality development \\
& Personnel development \\
& Selection of personnel \\
& Participation of pupils respectively parents \\
& National and international cooperation \\
\hline
\end{tabular}




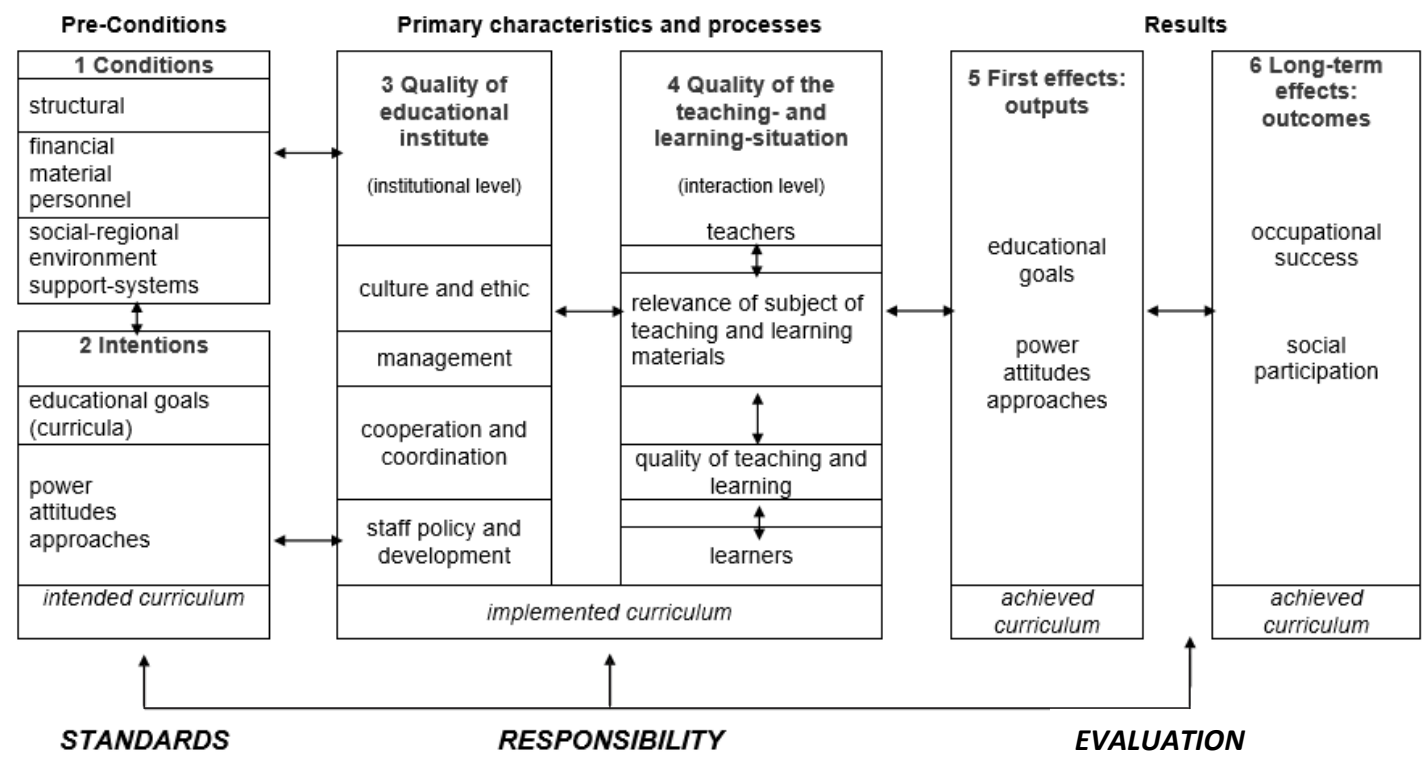

Figure 1. Model of Evaluation and Quality Securing in Education

The standards used for evaluation include utility standards, feasibility standards, accuracy standards, and propriety standards (Joint Committee on Standards for Educational Evaluation, 2000). Utility standards ensure that evaluation is directed to a specific purpose and will serve needs of intended users e.g. stakeholder identification, evaluator credibility, and competence. Feasibility standards ensure that an evaluation will be realistic, reasoned, diplomatic and easy, e.g. practical procedures, political viability, and cost-effectiveness. Propriety standards ensure that an evaluation will be conducted legally and ethically. e.g. service orientation, rights of the human subject, complete and fair assessment. Accuracy standards ensure that an evaluation will show and communicate adequate information on the features that determine worth or merit, e.g. described purposes and procedures, valid and reliable information, a justified conclusion

If the vocational educational institute is free in the decision, then it is possible to check, which could be the best for own institute, convincing for personnel and to accept by stakeholders. Advantageous is always to know different QMS, because it is possible to add some standards, criteria or instruments in the quality management of own institute. In addition, if it is not only for internal evaluation and development, but to follow external evaluation for getting a certificate, then the costs should be reviewed too.

Main steps for implementation of QMS consist of (1) communication process with whole staff. This is to make clear that quality securing and development needs the participation of all in the organization. It is not only a leadership task but it can only be successful, that especially teachers give proposals and feedback from learning teaching process as a core process of each educational institute, (2) discussion process on the understanding of quality and also aims of own institute. It is necessary to have a common quality understanding in an organization, which will be made concrete in each activity in different processes, (3) identification of current status. Under using suitable criteria is to analyze, which level of each standard is achieved. The criteria should be also developed and also suitable evaluation instruments together with teachers and other groups of staff, (4) development has to be planned e.g. feedbacks by teachers from lessons give the possibility, to follow the same programs or they can base, why and is to change the programs, (5) Practicable documents will be worked out. 
It needs e.g. short and understandable documentation of found data by evaluation or clearly arranged steps for same activity, (6) continuity of quality development will be secured by self-evaluation (internal audit). Teachers as experts in core process, teachinglearning process are essential in internal audit, and (7) management review by executives should be carried out for fixing the next concrete aims, steps, and responsibilities.

Teachers play vital and strategic roles in education (Alhamuddin, 2015). The education process will not work well, without the role of qualified teachers thus they are able to assist the institutions in carrying out Quality Management System (QMS) effectively. QMS QES ${ }^{\text {plus }}$ is quality development system in Saxony. This is a QMS developed by author and colleagues for institutes in continuing and adult education under support by Saxony; used since 2004, updated in 2017; can be used for internal and external evaluation by accredited certification agencies.

The following is given some examples of the role of teachers in QMS QES ${ }^{\text {plus. The first }}$ role is quality understanding. In quality understanding, fundamentals of own work will be explicated, especially understanding of teaching and learning. The quality understanding is transparent inside and outside. The quality of work will be systematic protected and developed (quality development circle). The criteria are (1) executive moderates immanent the communication on values of common work and protects their agreement, (2) She/he moderates the discussion on the understanding of teaching and learning under observation of respective target groups and secures agreements on these, and (3) She/he secures discussion and agreement of strategic aims of organization with the inclusion of staff also teachers and communicate aims of the organization. The second role is the development of offerings. The institute develops service offering on the basis of needs analysis as well as developments in the labor market and education market. For doing this it is useful to integrate expertise by teachers. The criteria are (1) results of labor market analysis and education market analysis, surveys of participants and surveys of the purchaser as well as needs analysis will be respected in development of education and counselor offerings, and (2) staff from pedagogical and administrative areas will be systematic participated. The third role is internal evaluation management. Quality understanding will be communicated to the institute. Institute uses suitable forms of communication for a guarantee of participative organizational development. Reflection has high significance for communication. Information access and handling of documents follow rules. Teachers are hereby integrated with communication and use also their reflection competence. The criteria are (1) the agreement on quality understanding will be enabled for all staff as meaningful orientation, (2) reflection possibilities of work quality will be given, (3) horizontal and vertical communication ways are used or rather created and (4) feedback routines will be established. Teachers are integrated with development feedback routines.

\section{CONCLUSION}

The quality assurance system is essential to be applied in vocational education to develop graduates which meet the needs of the world of work. Teachers work in core processes, learning and teaching processes. They need a good support by other core processes, like leading or managing and support processes. All activities in the vocational educational institutes are connected with teachers' work, so it is important to integrate teachers in securing and development quality. Teachers have high responsibility for quality securing and development. It is necessary that teachers understand their role in the quality process and have developed competencies for taking part in designing of quality processes and their evaluation. 


\section{REFERENCES}

Al-Ali, S. 2016. Quality Assurance System in Vocational Education and Training. International Journal of Management and Applied Science. 2.3. 90-92

Alhamuddin. 2015. Model Penjaminan Mutu Guru di Sekolah. Jurnal Penelitian dan Evaluasi Pendidikan.2.2,123-131

Cullingford, C. 2000. Assessment versus Evaluation. London: Cassell

Djatmiko, I.W. 2016. Study on the Empowering Teachers' Professional Development and Quality Assurance to Increase Teachers' Effectiveness in Vocational Secondary Schools. Jurnal Pendidikan Teknologi dan Kejuruan. 23. 2. 144-151

Ditton, H. 2002. Evaluation und Qualitätssicherung. In: Tippelt, R. (Hrsg.) Handbuch Bildungsforschung. Opladen

Fachhochschule Nordschweiz (University of Applied Sciences Northern Switzerland). 2007. Q2E Referenzrahmen (Q2E reference frame). Fachhochschule Nord schweiz

Felestin \& Triyono, M.B. 2015. The Implementation of Total Quality Management at Vocational High Schools in Indonesia. Research and Evaluation in Education Journal.1.1, 13-24

Gatt, S. \& Faurschou, K. 2016. Implementing the European Quality Assurance in Vocational Education and Training (EQAVET) at National Level: Some Insights from the PEN Leonardo Project. International Journal for Research in Vocational Education and Training. 3. 1, 29-45

Harvey, L. \& Green, D. 1993. Assessment and Evaluation in Higher Education. 18. 1, 934

Hopkins. D. 1996. Teaching and Teacher Education. 12. 5, 501-517. Elsevier Science. Ltd
Irimiea1, S \& Şerban, A. 2015. Quality Assurance Courses in VET (Vocational Education and Training) for Tourism Organised by the Centre Fortourism Training. Studia UBB Geographia. LX. 2, 171-184

K. Ismail, Z.M. Nopiah \& M.S. Rasul. 2017. Malaysian Teachers' Competency in Technical Vocational Education and Training: A review. Proceeding of Regionalization and Harmonization in TVET - Abdullah et al. (Eds). London: Taylor \& Francis Group

Landesamtes für Schule und Bildung (State Office for School and Education of Germany). 2014. Schulische Qualität im Freistaat Sachsen: Kriterienbeschrei bung (School Quality in the Free State of Saxony: Criteria description). Landes amtes für Schule und Bildung

Michalska-Ćwiek, J. 2009. The Quality Management System in Education Implementation and Certification. Journal of Achievement in Materials and Manufacturing Engineering. 37. 2, 749

Sächsisches Bildungsinstitut (Saxon Educational Institute). 2014. (Hsg.): Schulische Qualität im Freistaat Sachsen: Kriterienbeschreibung (School quality in the Free State of Saxony: Criteria Description). Dresden: Sächsisches Bildungsinstitut

Staatsinstitut für Schulqualität und Bildungsforschung (State Institute for School Quality and Educational Research). 2007. Qualitätsmanagement an Beruflichen Schulen (Quality Management at Vocational Schools). QmbS-Handbuch (QMBS manual). München: Staatsinstitut für Schulqualität und Bildungsforschung

Singh, H., Malhotra. R., \& Rassewatt, K. 2015. Qualitative Assessment for Improvement of Technical Education Using Total Quality Management: A Survey. International Research Journal of Engineering and Technology. 2.6, 888900 
Rossi, P., et al. 2004. Evaluation: A Systematic Approach $7^{\text {th }}$ edition. London: SAGE Publications

Spiel, C. 2001. Program Evaluation. In Neil J. Smelser \& Paul B. Baltes (Eds.) International Encyclopedia of the Social \& Behavioral Sciences. Oxford: Elsevier Science Ltd.

Unterausschuss für Berufliche Bildung (Subcommittee on Vocational Education) 2014. Qualitätsentwicklung an beruf lichen Schulen (Quality Development at Vocational Schools). Hrsg.: Sekreta-riat der Ständigen Konferenz der Kultus minister der Länder in der Bundes republik Deutschland Ed.: Secretariat of the Standing Conference of the Minister of Education of the Länder in the Federal Republic of Germany

Wiesner, G., et al. 2018. Organisationsentwicklung mit QES ${ }^{\text {plus }}$. (2017). Ulm: klemm + oelschläger

Wiesner, G. \& Knoll, J. 2006. Das qualitätsmanagement-system $\quad$ QES $^{\text {plus. }}$ Informationen und Erfahrungsberichte für potenzielle Anwender. https://www.weiterbildung.sachsen.de/do wnload/download_smk/br_qes.pdf

Yuniarti, N. 2014. Model Penyiapan Guru Pendidikan Kejuruan. Prosiding Konvensi Nasional APTEKINDO VII. 0$1,838-844$ 